\title{
Improvement of Educational Contents to Enhance the Efficiency of Construction Worksite Safety Training
}

\author{
Kim, Tae-Hui ${ }^{1}$ Ahn, Sungjin ${ }^{2} \quad$ Lee, Taick-Oun ${ }^{3} \quad$ Kim, Suk Bong ${ }^{4}$ Park, Young Jun ${ }^{4 *}$ \\ Department of Architectural Engineering, Mokpo National University, Muan-Gun, Jellanam-Do, 534-729, Korea ${ }^{1}$ \\ Department of Civil and Coastal Engineering, University of Florida, Gainesville, Florida, 32601, U.S.A. ${ }^{2}$ \\ Department of Architecture, Yeungnam College of Science and Technology, Nam-Gu, Daegu, 705-703, Korea ${ }^{3}$ \\ Department of Civil Engineering and Environmental Sciences, Korea Military Academy, Nowon-Gu, Seoul,
} 139-799, Korea $^{4}$

\begin{abstract}
The prevention of safety accidents can be achieved through Harvey's 3E's: Engineering, Enforcement, and Education. On construction sites, however, enforcement and engineering did not prove to be valid ways of reducing the number of safety accidents, as enforcement and engineering have failed to overcome and/or supplement the realistic limits regarding the relatively lower education levels of construction workers and the communication issues with foreign workers. On the other hand, safety education can enable the advancement of safety management by enhancing the educational contents and their methods of delivery. To improve the efficiency of safety education via educational contents, this research conducted a qualitative and quantitative analysis on the validity of the newly educational contents by overviewing possible accident types in different work phases. Of the accident types identified by the qualitative analysis, neither highly important nor insignificant accident types were found, yet all the suggested types are found to be required. In addition, this study did not find any significant differences in the occurrence probability of safety accidents related to the level of importance of each type of accident. The qualitative analysis in this research verified that the suggested accident types can be valid, educational material that can take into account future safety accidents.
\end{abstract}

Keywords : construction safety, occupational safety and health administration (OSHA), education efficiency, qualitative and quantitative analysis

\section{Introduction}

\subsection{Research background and purpose}

Despite the fact that almost 30 percent of all workplace deaths from safety accidents occur in the construction industry, safety management has received little attention[1]. By its nature, construction industry work involves constant

Received : December 23, 2012

Revision received : January 4, 2013

Accepted : January 6, 2013

* Corresponding author : Park, Young Jun

[Tel: 82-2-2197-2853, E-mail: yjpark@kma.ac.kr]

(c)2013 The Korea Institute of Building Construction, All rights reserved. exposure to a hazardous environment. The lack of a high technology labor force due to the avoidance of 3D work along with an aging labor force has led to a relatively higher risk of safety accidents[2]. But since construction work mainly involves production cost, process and quality for its management, the need for safety management has rarely been recognized[3].

The core of safety management is the prevention of safety accidents, and this starts with being educated in safety accident prevention. Harvey's Three Es calls for the efficient management of Engineering, Enforcement, and Education[4]. To prevent safety accidents, construction work sites 
are introducing and applying strict regulations, codes and a variety of equipment and devices $[5,6]$. Nevertheless, actual construction sites have not shown a noticeable decrease in safety accidents, owing to the fact that the regulations and technologies have not been successful in overcoming and supplementing the realistic limits regarding the relatively lower educational levels of construction workers and the issues related to communication with foreign workers[7,8]. Rather than depending on technologies and regulations, education can serve as the ultimate means for improving safety management standards.

Enhancing safety education can be achieved by advancing the methods of delivery and educational contents. The contents of the previous safety education program have proven to be overly simplistic and thus ineffective. The education methods have proven to be ineffective in drawing learner attention and interest, and have failed to promote educational achievement $[9,10,11,12,13]$.

To improve the efficiency of the contents of safety education material, this research covers possible accident types in different construction settings, and assesses the validity of safety education through a qualitative and quantitative analysis.

\subsection{Research scope and strategy}

As a part of the research project to improve education on the prevention of safety accidents, the scope of this research is limited to increasing efficiency in which its contents are expressed in prevention education. In addition, this research mainly focuses on safety education for site workers in a condominium construction site rather than a comprehensive construction site.

The procedures used in this research are as follows. The research 1) selected and organized work type and details for accident types applicable only to condominium construction sites of the several hundred safety accident checklist items suggested by the Occupational Health and Safety Administration (OSHA). The organized accident types were then classified depending on the occurrence intensity and management importance through a Likert Scale conducted by construction site managers and scholars in the related field. The purpose of this classification was to allow the weighting value with respect to the occurrence intensity and management importance for each accident type, to support the efficiency of prevention education for safety accidents, since each accident type yields varying probability. To examine the validity of the assigned weighted value, a qualitative analysis has been conducted on the actual probability of the suggested accident types of safety accident in military Built-To-Lease (BTL) projects. Various factors limit the researcher's ability to accurately determine the rate of occurrence of safety accidents, including failure to report, negligence of safety management, and a corporation's fear of harming its public image. In military BTL projects, the reporting structure is rather stringent, meaning that a relatively accurate aggregation of safety accidents is possible; yet the construction scale is not large enough to generalize the figure as the entire safety accident. For this reason, this research conducted a qualitative analysis through surveys, and a quantitative analysis through data investigation.

\section{Literature reviews}

\subsection{Education efficiency and effectiveness}

Improvements in the safety education level can be achieved by developing educational contents to raise the efficiency of safety accident prevention 
and by enhancing the methods of delivery of said contents to raise the effectiveness of learning $[14,15,16]$.

Efficiency and effectiveness can be conceptualized as "Doing Things Right" and "Doing Right Things" [17]. Effectiveness means the production level, i.e., production quality, is under a fixed input by the variable system and is relevant to the accuracy of education. In other words, effectiveness takes into account the accuracy of education, which equals the level of education as a result from an education method in the same amount of training hours. Thus, in order to improve the education level within the time allowed for education, a change in the education method is essential, and this is an attainable improvement to enhancing the way education is delivered. On the other hand, efficiency means the production level, i.e., production quantity, is under a fixed system by the variable input. That is, efficiency takes into account the swiftness, which is equivalent to the level of education as a result depending on the training hours using the same educational method. Therefore, shortened training hours, a variable factor, are necessary in maintaining the required education level if the same education method is to be maintained; this will become practical through improving educational contents by shortening the training hours.

\subsection{Safety education for accident prevention}

Various studies have confirmed that preventive safety education is the most effective means of reducing safety accidents. Previous studies have indicated common problems and suggested the means to ameliorate the problems; for example, current safety training causes inefficiency in the learning process by including too many or unnecessary accident types in the contents, and pursuing an ineffective training method that does not satisfy the worker's interest.[9,10,11,12,13]. Table 1 summarizes these studies.

\section{Deduction of safety accident types}

The U.S. OSHA has suggested a checklist for safety accident prevention and the standard for educational issues; however, it is impractical to apply the checklist and the standards to a Condominium Construction Site worksite. OSHA, under the United States Employment Service,

Table 1. Safety education for accident prevention

\begin{tabular}{|c|c|c|}
\hline Author & Problems with current Safety training & Improvement Plan \\
\hline Korea OSHA[1] & $\begin{array}{l}\text { Lack of worker interest } \\
\text { Training not tailored to work categories } \\
\text { Lack of efficiency and diversity of education } \\
\text { methods }\end{array}$ & $\begin{array}{l}\text { Diversification of educational methods and institutions } \\
\text { Enhancing of on-site training }\end{array}$ \\
\hline Yoo[11] & $\begin{array}{c}\text { Non-compliance with regulatory training time } \\
\text { Unsuitable work for education level } \\
\text { Lack of worker interest }\end{array}$ & $\begin{array}{l}\text { Systematization and diversification of training methods } \\
\text { Strengthen the management of training regulations }\end{array}$ \\
\hline $\operatorname{Kim}[9,10]$ & $\begin{array}{c}\text { Education ignores site condition } \\
\text { Education ignores level of worker education } \\
\text { Shortage of training contents }\end{array}$ & $\begin{array}{c}\text { Consideration of workers' individual characteristics and site } \\
\text { condition } \\
\text { Safety accident case education }\end{array}$ \\
\hline $\operatorname{Kim}[12]$ & $\begin{array}{l}\text { No consideration of personal characteristics } \\
\text { Lack of training by work type and Hierarchy }\end{array}$ & Model development to adjust for workers' individual personalities \\
\hline Jang[13] & $\begin{array}{c}\text { Low safety prevention consciousness among } \\
\text { workers } \\
\text { Lacks of safety education and relevance of work }\end{array}$ & $\begin{array}{l}\text { Revitalization of the authorized instructors } \\
\text { Revitalization of the empirical safety training }\end{array}$ \\
\hline
\end{tabular}


establishes sanitation and safety, provides training, and manages the statistical data related to diverse safety accidents. The prevention standard for safety accidents, Construction Standard (29CFR1926), suggested by OSHA, describes in detail a few hundred components for work categories in construction worksites.

The OSHA safety accident prevention education and worksite inspection includes too many items; specifically, it suggests standards that are applicable to a varying number of accidents in any type of worksite, its effectiveness for safety management in Condominium construction worksites is rather lacking[8]. In fact, the OSHA standards are selectively applied to worksite safety management depending on the construction worksite categories; these, in turn, call for efficient safety management standards that are applicable to Korean Condominium construction worksites, which amount to more than 70 percent of general residences[9]. The following is an excerpt, from OSHA standards, of items relevant to Condominium construction worksites in support of efficient improvements to the safety accident prevention education.

Table 2 categorizes the excerpted items by 11 work sections and 36 specific works; each detail also includes a variety of accident types. In this paper, the major safety accident types, which are ranked at more than 3.0 points in both occurrence severity and management importance aspects, are present.

\section{Validity assessment of the selection criteria}

\subsection{Qualitative analysis}

Of the accident categories selected from the qualitative analysis, neither highly important nor insignificant accident types were found; suggested overall accident type are required properly. This was proven to be valid through the Likert Scale survey of construction site managers and scholars in the field on accident occurrence severity and management importance.

In Table 2, rows 4 and 5 include the mean score of responses for the survey on the occurrence severity and management importance of accident categories measured through the Likert Scale. The average age of the 165 respondents was 40.8 years old, and the average years of experience in worksite management or research experience in the related field was 12.8 years. In terms of the appropriateness for the suggested standards, an average of 2.982(Normal) was suggested; regarding individual item scores, no significant distinctions between different items were found, yet the need for occurrence severity and management importance was found. With respect to the worksite experiences, 38 percent of all respondents, approximately 63 respondents, had experience working as a site manager and their average age was 43.1 years old, with average years of worksite management of 15.1 .

Concerning the adequacy of the suggested standards, an average of 3.048(Normal) was shown. In addition, each item was shown to need the occurrence severity and management importance, and there was no significant difference between each item's score. That is, with reference to the adequacy of the suggested standards for worksite safety education, the entire respondent group, as well as the group of respondents with worksite manager experience, yielded little difference, being more or less "3(Normal)"; between each item. Also, no significant difference in the scores was found, which proves that all the accident categories were adequately met. 
Table 2. Applicable safety accident types of OSHA for condominium construction sites

\begin{tabular}{|c|c|c|c|c|}
\hline $\begin{array}{l}\text { Work } \\
\text { Type }\end{array}$ & Details & Safety Accident types & $\begin{array}{l}\text { Occurrence } \\
\text { Severity }\end{array}$ & $\begin{array}{l}\text { Management } \\
\text { Importance }\end{array}$ \\
\hline Temporary & Scaffold/safety net & Falling object while carrying materials & 3.267 & 3.830 \\
\hline Temporary & Scaffold/safety net & $\begin{array}{l}\text { Fall due to not wearing personal protective equipment during erecting and } \\
\text { dismantling }\end{array}$ & 3.345 & 4.006 \\
\hline Temporary & Scaffold/safety net & Falling object during erecting and dismantling & 3.552 & 4.012 \\
\hline Earth & Const. equipment & Crash due to not wearing personal protective equipment (PPE) & 3.000 & 3.685 \\
\hline Earth & Excavation & Fall or tumble down an excavation site edge & 3.024 & 3.758 \\
\hline Earth & Excavation & Hit into the back side while excavating equipment is rotating & 3.176 & 3.733 \\
\hline Earth & Excavation & Collapse of excavation side due to over cutting slope or over-excavation & 3.248 & 3.915 \\
\hline foundation & Pile driving & Equipment collapse due to ground sinking of the underbody of equipment & 3.109 & 3.964 \\
\hline foundation & Pile driving & Impact between equipment and labor working under equipment & 3.030 & 3.642 \\
\hline foundation & Pile driving & Collapse of the operating driving pile machine & 3.085 & 3.891 \\
\hline Structure & Preparation & Falling material by single wire while carrying freight & 3.073 & 3.715 \\
\hline Structure & Gang form & Fall due to non-installation of safe guard-rails on work platform for form installation & 3.345 & 3.921 \\
\hline Structure & Gang form & Fall due to non-installation of opening cover during installation of form & 3.370 & 3.982 \\
\hline Structure & Rebar assembly & Being impaled by rebar while working without wearing PPE & 3.012 & 3.497 \\
\hline Structure & Shore & Fall due to non-installation of safe guardrails on movable scaffolding & 3.236 & 3.836 \\
\hline Structure & Shore & Collision with shore while not wearing PPE & 3.024 & 3.521 \\
\hline Structure & Concrete pour & Collapse of shore while pouring concrete & 3.261 & 4.097 \\
\hline Structure & Form removal & Dropping of form on the worker during removal & 3.303 & 3.764 \\
\hline Structure & $\begin{array}{l}\text { FormForm removal } \\
\text { removal }\end{array}$ & Fall by applying excessive strength while removing form & 3.248 & 3.685 \\
\hline Masonry & Masonry & Fall caused by lack of safety measures around openings & 3.097 & 3.794 \\
\hline Masonry & Masonry & Fall due to failure to install elevating ladder \& safety guardrail on movable scaffolding & 3.188 & 3.745 \\
\hline Plaster & plaster work & Fall caused by poorly installed scaffolding and work plate & 3.164 & 3.794 \\
\hline Plaster & plaster work & Fall caused by unfastened rope on suspended scaffolding during plaster work & 3.042 & 4.042 \\
\hline Plaster & plaster work & Fall due to non-installation of safety guardrails on movable scaffolding & 3.188 & 3.964 \\
\hline Water proofing & Membrane & Improper installation of movable scaffolding when working at a high altitude & 3.158 & 3.788 \\
\hline Water proofing & Membrane & Fall due to noncompliance of protective measures, including safety guardrail & 3.085 & 3.630 \\
\hline Water proofing & Finish & Falling openings while cleaning the opening covers & 3.000 & 3.691 \\
\hline Roofing & Preparation & Falling materials due to lifting materials with improperly bound tower crane & 3.061 & 3.794 \\
\hline Roofing & Preparation & Falling materials due to unstable loading on the top of sloped roof & 3.212 & 3.891 \\
\hline Roofing & Preparation & Falling materials due to using a single wire when lifting light gauge steel materials & 3.097 & 3.782 \\
\hline Roofing & Installation & Falling materials due to wind while installing roof truss & 3.206 & 3.830 \\
\hline Window/Door & Installation & Fall due to losing balance while finishing building edges & 3.230 & 3.952 \\
\hline Window/Door & Window/Door & Leaning out too far when caulking at window frames & 3.109 & 3.885 \\
\hline Painting & Preparation & Fall due to not fastening scaffolding belt or rope with vertical lifeline & 3.091 & 3.952 \\
\hline Painting & Preparation & Fall during surface treatment on work platforms & 3.000 & 3.752 \\
\hline Painting & Painting & Fire while painting near welding work place & 3.164 & 3.964 \\
\hline Painting & Painting & Fall while using ladder when working at a high altitude & 3.200 & 3.964 \\
\hline Electric/Mech. & Electric/Mech. & Fall from ladder during wiring work & 3.067 & 3.727 \\
\hline Electric/Mech. & Electric/Mech. & Fire or explosion caused by an electrical spark & 3.042 & 3.764 \\
\hline Electric/Mech. & EN & $\begin{array}{c}\text { Fall into openings on machine room floors or on each floor while carrying materials } \\
\text { into pits }\end{array}$ & 3.103 & 3.818 \\
\hline Electric/Mech. & EN & Fall due to failure to install safety railing on elevator floor and ceiling edge & 3.061 & 3.867 \\
\hline
\end{tabular}


The writing survey has confirmed scores that were lower than expected, which means that rather than the safety education at the sites being unimportant or ineffective, safety education is not being sufficiently realized in the construction sites. With most individual items, the fact that occurrence severity is relatively higher than management importance was evidence that the respondents were more interested in the prevention of accidents that the occurrence of accidents. To draw a more specific result, further and more meticulous research is called for.

\subsection{Quantitative analysis}

The quantitative analysis has confirmed that the suggested standards would contribute to improving the efficiency of safety accident education. The data concerning safety accidents at construction sites for the military BTL official residence, which is reserved by the Korean Defense Installations Agency, was used to examine whether the accident categories illustrated in Table 2 are included in the range of the actual occurrence of safety accidents. Table 3 demonstrates that the OSHA standards and the types of accidents suggested in this research have a few of the non-included safety accidents that actually took place in the corresponding projects. The results show that the types of accidents that occurred at construction sites include all types of accidents indicated by the OSHA as well as by this research. It is noteworthy that even though this research has eliminated a considerable number of accident categories compared to the OSHA, the efficiency of safety education can be increased significantly in a limited time, as there are only a few non-included accident categories.

\subsection{Validity Assessment}

The quantitative analysis demonstrated that there was little significance in placing a weighted value between each type of accident, as there are

Table 3. Rates of non-included safety accidents in the military BTL projects

\begin{tabular}{|c|c|c|c|c|c|}
\hline Region & $\begin{array}{l}\text { Budgets } \\
(B \#)\end{array}$ & $\begin{array}{l}\text { Period } \\
\text { (days) }\end{array}$ & Project type & \multicolumn{2}{|c|}{$\begin{array}{c}\text { Excluded } \\
\text { Accident }(\%)\end{array}$} \\
\hline Region & $\begin{array}{l}\text { Budgets } \\
(\mathrm{B} \#)\end{array}$ & $\begin{array}{l}\text { Period } \\
\text { (days) }\end{array}$ & Project type & OSHA & $\begin{array}{l}\text { This } \\
\text { study }\end{array}$ \\
\hline Seoul / Gyeonggi & 88.5 & 752 & $\begin{array}{c}\text { Condominiums } \\
\text { Quarters }\end{array}$ & - & - \\
\hline Gangwon & 79.5 & 779 & Residence & - & - \\
\hline Gangwon & 193.3 & 866 & $\begin{array}{l}\text { Condominiums } \\
\text { Barracks }\end{array}$ & 1.01 & 1.01 \\
\hline Daejeon & 181.6 & 858 & Condominiums & - & - \\
\hline Gyeonggi & 99.7 & 783 & $\begin{array}{l}\text { Condominiums } \\
\text { Barracks }\end{array}$ & - & - \\
\hline Gyeonggi & 112.5 & 825 & $\begin{array}{l}\text { Condominiums } \\
\text { Quarters }\end{array}$ & - & - \\
\hline Gyeonggi & 958 & 779 & $\begin{array}{c}\text { Condominiums } \\
\text { Quarters }\end{array}$ & - & - \\
\hline Daegu & 65.8 & 719 & $\begin{array}{l}\text { Condominiums } \\
\text { Barracks }\end{array}$ & - & 1.67 \\
\hline Daejeon & 166.3 & 826 & Barracks & - & - \\
\hline Gyeonggi & 157.3 & 817 & $\begin{array}{l}\text { Condominiums } \\
\text { Quarters }\end{array}$ & - & - \\
\hline
\end{tabular}




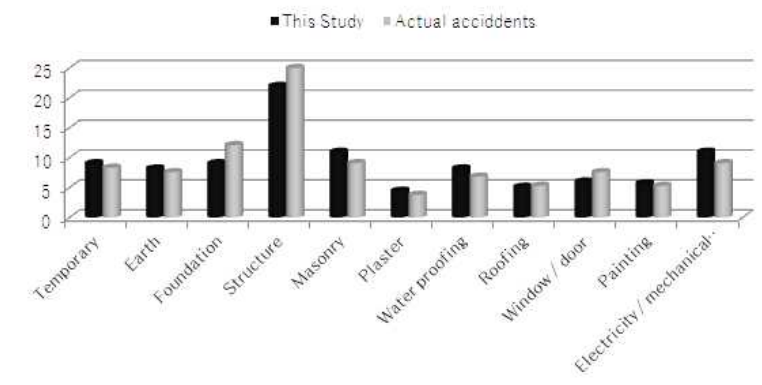

Figure 1. Comparison between safety accidents probability by work types identified this study and military projects

no meaningful differences among them. When placing the same weight on the types of accidents indicated in this research - assuming that the probabilities for individual accident types are equal - the comparison between the occurrence probability of accidents corresponding to each work category out of the possible accidents and accident rate classified by work category as a percentage of all accidents that took place in construction sites for BTL projects was limited due to a lack of collected data.

For this reason, in order to indirectly examine the comparison, this research compared the probability of safety accident occurrence by work type, instead of by category of accident, to the suggested accident type and the data regarding safety accidents in the actual military BTL official residence construction worksites. Figure 1 illustrates the probability of safety accidents in each work category, which includes corresponding accident categories, and is substantially similar to the types of actual safety accidents in the BTL worksites for official military residence. In other words, the score differences found in the survey of the accident categories are not meaningful, which implicitly supports the premise that the occurrence probability of each accident category is similar, and thus placing the same weighted value on the categories is permissible. But for a more detailed assessment of the probability, more reliable and comprehensive data collection is required. In addition, as we were not authorized by the Korean Defense Installations Agency to demonstrate the aggregated data concerning safety accidents in the military BTL official residence project, the accident rates classified by work category as a percentage of all accidents that took place in construction sites were the only possible data to be suggested.

\section{Conclusion}

Despite the fact that almost 30 percent of workplace deaths related to safety accidents take place in the construction industry, safety management still receives little attention. The core of safety management is the prevention of safety accidents, and this starts with being educated in safety accident prevention. Enhanced safety education can be achieved by advancing the method of education delivery and simplifying its contents.

To improve the efficiency of understanding safety educational contents, this research conducted a qualitative and quantitative analysis of the validity of said safety education contents by selecting possible accident categories by work phase. Of the several hundred safety accident checklist items suggested by the Occupational Health and Safety Administration this study selected and organized by work type and details the accident categories applicable to Condominium construction sites. The organized accident categories were then classified by occurrence severity and management importance through the Likert Scale survey given to construction site managers and scholars in the field.

To examine the validity of assigned weighted values, a qualitative analysis was conducted on the 
actual probability of the suggested accident categories of safety accidents in military BTL projects. Of the accident categories selected from the qualitative analysis, neither highly important nor insignificant accident categories were found; suggested overall accident categories are required properly.

The quantitative analysis has demonstrated little significance in placing a weighted value between each type of accident, as there are no meaningful differences among them. The qualitative analysis in this research verified that the suggested accident types can be valid, education contents that can take into account future safety accidents. Yet, for a more detailed assessment of the probability, more reliable and comprehensive data collection is required. The findings of this research will facilitate improvements in the effectiveness of safety education by applying Building Information Modeling, and will be used as fundamental data for future research, which will statistically assess the effectiveness of the safety education model using the Charrette Test Method.

\section{Acknowledgement}

This research was supported by a grant (No.2012010882) fromm the National Research Foundation of Korea(NRF) by Ministry of Education, Science and Technology(MEST).

\section{References}

1. Occupational Safety and Health Research Institute (OSHRI). [Internet]. Incheon: Industirial Accidents analysis; c2003-2011 [updated 2012 Feb 22; cited 2012 Jun 12]. OSHRI Occupational Safety Research Department. Available From: http://oshri.kosha.or.kr/board?tc=RetrieveBoardViewCmd\&board Type=A\&contentId=343896\&pageNum=1\&urlCode=T1 | | 3307| 369 | 369 | 3307| 3308 | |/content/disaster/analysis.html |Y\&tabId=3310
2. Park DH. A Study on the Effectiveness of Accident Prevention for the Construction Site Using Construction Safety Education. Incheon (Korea): Occupational Safety and Health Research Institute (OSHRI); c1997. 223 p.

3. Lee, HS, Kim, HS, Park, MS. Construction Risk Assessment Using Site Influence Factors. Journal of Computing in Civil Engineering. 2012 May;26(3):319-30.

4. Ahn SH, Ryu HW, Park MS. Selecting Key Accident Risk Factors in Building Construction Projects. Journal of the Korea Institute of Building Construction. 2011 Jan;11(1):45-50.

5. Lee HS, Lee GP, Park MS, Kim HS. A Construction Safety Management System Based on Building Information Modeling and Real-time Locating System. Korean Journal of Construction Engineering and Management.. 2009 Nov;10(6):135-45.

6. Abderrahim M, Garcia E, Diez R, Balaguer C. A mechatronics security system for the construction site. Automation in Construction. 2005 Aug;14(4):460-6.

7. Son CB. An Analysis on the Employment of Foreign Laborer in Domestic Construction Fields. Journal of Architectural Institute of Korea. 2005 Jun;21(6):105-12.

8. Han SH, Park, SH, Jin EJ, Kim HK, and Seong YK. Critical Issues and Possible Solutions for Motivating Foreign Construction Workers, Journal of Management in Engineering. 2008 Oct;24(4):217-26.

9. Kim EJ, Kim KR, Shin DW, A Model for Safety Education Fit for Individual Personality of Construction Worker. Korean Journal of Construction Engineering and Management. 2008 Oct;9(5):116-26.

10. Kim EJ, Kim KR, Shin DW, Improvement for Safety Education Considering Individual Personality in the Construction Site, Korean Journal of Construction Engineering and Management. 2008 Jun;9(3):175-84.

11. Yoo SI, Kim YS. A Study on the Survey for Current Status of Construction Safety Education and Workers' Safety Consciousness, Journal of Architectural Institute of Korea. 2000 Apr;20(1):156-65.

12. Kim MJ. Improvement plan of construction safety education for accident prevention in construction site [master's thesis]. [Seoul (Korea)]: Dongguk University; 2003. 82 p.

13. Jang KK. A Study on the Improvement of New Employees Safety Education for Preventing the Traditional Industrial Accidents in the Construction Industry [master's thesis]. [Gyeongnam (Korea)]: Inje University; 2011. 61 p. 
14. Fr økjær E, Hertzum M, Hornbæk K. Measuring usability: are effectiveness, efficiency, and satisfaction really correlated?. In: Korhonen P, Tscheligi M, Miller J, Jeffries R, editors. Proceedings of the SIGCHI conference on Human Factors in Computing Systems; 2000 Apr 1-6; Hague, Netherlands. New York (NY): ACM Digital Library; c2000. p. 345-52.

15. Burke M, Sarpy S, Salvador R, Islam G. Relative Effectiveness of Worker Safety and Health Training Methods. American Journal of Public Health. 2006 Feb;96(2):315-24.

16. Jeng J. Usability Assessment of Academic Digital Libraries: Effectiveness, Efficiency, Ssatisfaction, and Learnability. International Journal of Libraries and Information Services, 2008 January; 55(2-3):96-121.

17. Drucker PF. Management: Tasks, Responsibilities, Practices. London (UK): HarperBusiness; c1993, 864 p. 